\title{
Trolley Operated Automatic Discharge System (TOADS)—An Automated System for Horizontal Profiling of Water Velocity and River Discharge Measurements
}

Hydroacoustics have revolutionized how the U.S. Geological Survey (USGS) measures streamflow by increasing the efficiency and quality of the measurement. However, the ability to determine the full range of streamflow at a streamflow-gaging station remains limited because in-person flow measurements still must be made by qualified personnel. As a result, streamflow during flood events typically is measured infrequently in comparison to the duration of the event, usually after the peak flow has occurred. To overcome these difficulties, the USGS has developed the Trolley Operated Automatic Discharge System (TOADS), an automated system for measuring streamflow without the need for onsite personnel. Investment by USGS in TOADS and other innovative technologies and methods provides substantial improvements to flood assessment and watershed management, making the USGS the continued world leader in surfacewater hydrology.

Streamflow measurements made with TOADS are analogous to a moving-boat measurement, which measures the flow at a point in a river by moving from bank to bank and measuring water velocities at various depths below the boat. The TOADS uses hydroacoustic technology to profile water velocity across a river while moving vertically through the water column to measure flow at multiple depths. Use of TOADS to measure streamflow can save substantial time and money, provide improved flow ratings by taking numerous targeted automated measurements over a range of conditions, and provide a safe alternative to standard boat measurements when river conditions are hazardous. The TOADS can be programmed to measure flow based on a variety of triggers (including river stage, amount of flow, time of day) and can take repeated measurements at user-specified intervals during floods, droughts, and other events of interest.

\section{How it Works}

The TOADS consists of an acoustic Doppler velocity meter (ADVM) mounted on a vertical I-beam positioned on the bank of the waterbody (fig. 1). The I-beam extends from above the land surface to the bottom of the channel. An electric motor and small chain-driven cart moves the ADVM up and down the I-beam. A signal from a

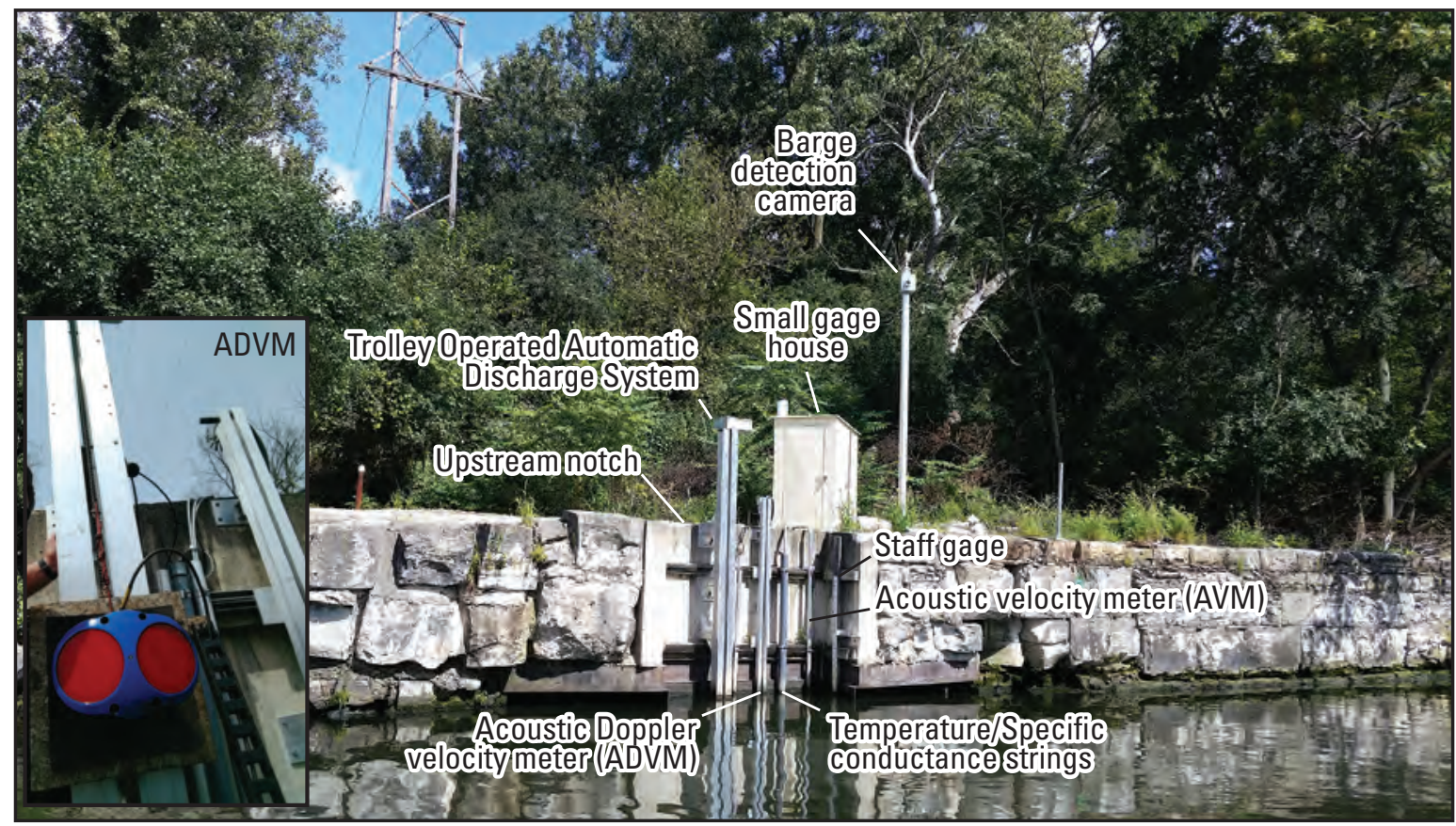

Figure 1. Photograph showing the Trolley Operated Automatic Discharge System (TOADS) deployment at Chicago Sanitary and Ship Canal near Lemont, Illinois (U.S. Geological Survey streamflow-gaging station 05536890). 
datalogger attached to the TOADS initiates the flow measurement based on pre-determined criteria. The TOADS measures in the following sequence:

1. A sensor in the TOADS measures the water level from its "home" position near the bottom of the stream. The program in the datalogger computes the height of the water column and the position of the $30-, 40-, 50-, 60-$, and 70-percent depths of the stream channel. Each of these depths is a point of measurement for the ADVM, creating five horizontal profiles. The datalogger is stored in the gage house.

2. The TOADS moves the ADVM up the I-beam, stopping at each pre-selected depth to measure horizontal profiles of stream velocity across the width of the stream channel. Each horizontal velocity profile is divided into 10 segments of equal length. Twodimensional velocity data are collected for each of the 10 stream segments at each of the five depths (fig. 2).

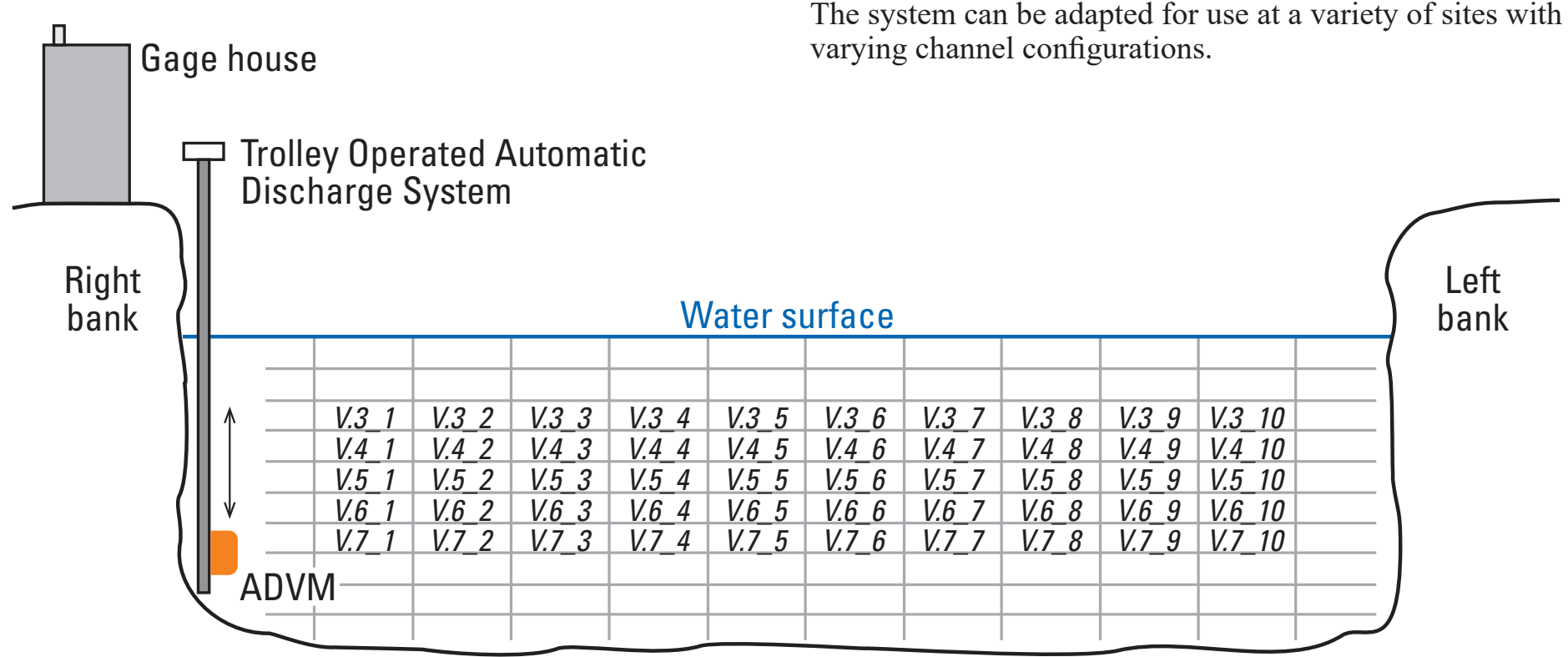

3. After completing the five horizontal profiles, the ADVM returns to its "home" position and the stage sensor records a final measurement of the water level. The datalogger then computes flow from the measured velocity field using adapted USGS methods and stores the data.

4. The process is repeated at pre-programmed intervals when conditions determined by the investigators occur.

Additional components of the system are used to ensure the integrity of the measurement. The camera enables identification of periods when barge traffic can disrupt the measurement. The notch in the canal wall prevents damage from barge traffic.

The TOADS can take more flow measurements and more targeted measurements at lower cost and with less risk to field personnel than current methods of measurement. Installation of the system can be temporary or permanent depending on the needs of the monitoring effort. The system can be adapted for use at a variety of sites with varying channel configurations.

Figure 2. Schematic cross-section of the Chicago Sanitary and Ship Canal near Lemont, Illinois (U.S. Geological Survey streamflow-gaging station 05536890), showing the Trolley Operated Automatic Discharge System (TOADS) deployment and the portion of the cross section measured by the TOADS acoustic Doppler velocity meter (ADVM).

For more information about this publication, contact:

Director, USGS Central Midwest Water Science Center 405 North Goodwin

Urbana, IL 61801

217-328-8747
For additional information, visit: https://www.usgs.gov/centers/cm-water

Publishing support provided by the Rolla and Sacramento Publishing Service Centers 